\title{
Effect of Laparoscopic Surgery on the Initiation and Completion of Chemotherapy in Patients With Colon Cancer
}

\author{
Min-Ki Kim, Won-Kyung Kang \\ Department of Surgery, Seoul St. Mary's Hospital, College of Medicine, The Catholic University of Korea, Seoul, Korea
}

\section{See Article on Page 274-279}

The developments in colon cancer treatment over the past two decades can be found largely in chemotherapy and laparoscopic surgery. Adjuvant chemotherapy increases survival in stage III and select stage II colon cancer patients $[1,2]$. Reports in the literature have indicated that delaying the initiation of adjuvant chemotherapy for longer than eight weeks after surgery or after failure to complete adjuvant chemotherapy adversely affects the overall survival of colon cancer patients $[3,4]$. Laparoscopic surgery has several benefits in cosmesis, postoperative length of hospital stay, analgesics usage and return of bowel function while it is comparable in survival to open surgery. Therefore, many large-volume centers use laparoscopic surgery as the mainstay in colon cancer treatment.

However, few studies deal with the effect of laparoscopic surgery on the initiation or completion of adjuvant chemotherapy in colon cancer patients. In a previous study [5], only $67 \%$ of patients were reported to have completed their chemotherapy. If those effects of laparoscopic surgery are proven, some chance may exist to improve colon cancer survival by increasing compliance with chemotherapy. Recently, Gantt Jr et al. [6] reported no difference in proportions of patients who received adjuvant chemotherapy more than eight weeks after surgery between the laparoscopic and the open surgery groups. Their notable finding was that the delay in the initiation of adjuvant chemotherapy adversely affected patients' disease-free and overall survival in the open surgery group, but not in both of the laparoscopic surgery group.

\section{Correspondence to: Won-Kyung Kang, M.D.}

Department of Surgery, Seoul St. Mary's Hospital, College of Medicine, The Catholic University of Korea, 222 Banpo-daero, Seocho-gu, Seoul 137-701, Korea

Tel: +82-2-2258-6104, Fax: +82-2-595-2822,

E-mail: wonkkang@catholic.ac.kr

(C) 2014 The Korean Society of Coloproctology

This is an open-access article distributed under the terms of the Creative Commons Attribution NonCommercial License (http://creativecommons.org/licenses/by-nc/3.0) which permits unrestricted noncommercial use, distribution, and reproduction in any medium, provided the original work is properly cited.
Although the article has several limitations and shortcomings, vague follow-up period, uncertainty of whether cancer-specific survival was calculated or not, unclear relationship between chemotherapy completion rate and survival, no significant difference in the chemotherapy completion rate and a significant difference in survival rate between the laparoscopic surgery and the open surgery groups were noted [7]. Further studies dealing with the issue of laparoscopic surgery and chemotherapy compliance are expected to be spurred by the publication of this study.

\section{REFERENCES}

1. Moertel CG, Fleming TR, Macdonald JS, Haller DG, Laurie JA, Goodman PJ, et al. Levamisole and fluorouracil for adjuvant therapy of resected colon carcinoma. N Engl J Med 1990;322:352-8.

2. Quasar Collaborative Group, Gray R, Barnwell J, McConkey C, Hills RK, Williams NS, et al. Adjuvant chemotherapy versus observation in patients with colorectal cancer: a randomised study. Lancet 2007;370:2020-9.

3. Biagi JJ, Raphael MJ, Mackillop WJ, Kong W, King WD, Booth CM. Association between time to initiation of adjuvant chemotherapy and survival in colorectal cancer: a systematic review and meta-analysis. JAMA 2011;305:2335-42.

4. Dobie SA, Baldwin LM, Dominitz JA, Matthews B, Billingsley K, Barlow W. Completion of therapy by Medicare patients with stage III colon cancer. J Natl Cancer Inst 2006;98:610-9.

5. van der Geest LG, Portielje JE, Wouters MW, Weijl NI, Tanis BC, Tollenaar RA, et al. Complicated postoperative recovery increases omission, delay and discontinuation of adjuvant chemotherapy in patients with Stage III colon cancer. Colorectal Dis 2013;15:e582-91.

6. Gantt GA Jr, Ashburn J, Kiran RP, Khorana AA, Kalady MF. Laparoscopy mitigates adverse oncological effects of delayed adjuvant chemotherapy for colon cancer. Surg Endosc 2014 [Epub]. http:// dx.doi.org/10.1007/s00464-014-3697-1.

7. Chun KH, Bae BN, An H, Jeong H, Cho H, Gwak G, et al,. Comparison of compliance of adjuvant chemotherapy between laparoscopic and open surgery in patients with colon cancer. Ann Coloproctol 2014;30:274-9. 